\title{
Peertechz
}

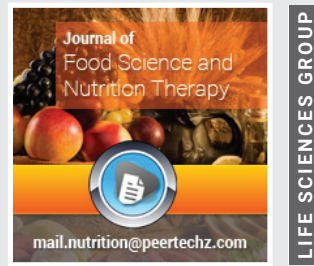

\section{Nutritional and Health Benefits of Donkey Milk}

\section{Bhairav Prasad*}

Vidya Jyoti Institute of Higher Education, Derabssi SAS Nagar -140508 (Punjab), India

Received: 22 September, 2020

Accepted: 01 October 2020

Published: 03 October, 2020

*Corresponding author: Bhairav Prasad, Vidya Jyoti Institute of Higher Education, Derabssi SAS Nagar -140508 (Punjab), India,

E-mail: bhairavmicro@gmail.com

Keywords: Donkey; Immunity; Milk; Neutracuticals https://www.peertechz.com

Check for updates

\section{Abstract}

Donkey/ass/jenny milk is the milk that is produced by female donkey (Equus asinus) Due to small udder size the quantity produced is very less hence difficult to commercialize. It has been used since ancient times for infant nutrition as well as cosmetic purposes. In the late $20^{\text {th }}$ century the donkey milk was used to feed orphaned infants and cure weak and sick children due to its resemblance with the human breast milk. Due to exceptionally high proximity with human breast milk the donkey are domesticated in Greece, Italy, Belgium, Germany, Switzerland and some other parts of European world. The donkey milk composition shows resemblance to human breast milk for lactose, protein and ash when compared with goat, sheep, cow and camel milk. Several scientific study has proven that the donkey milk contain several active ingredients that boost the immunity and other health benefits. Among functional the donkey milk contains active antimicrobial substance such as lysozyme and lactoferrin. These molecules are also present in goat, sheep and cow milk but in less quantity. The donkey milk also contains less fat and cholesterol than cow, goat and sheep milk. Therefore this milk is best for the cardiovascular or heart patients.

\section{Introduction}

The donkey milk is closet to cow milk. It may sound like a trendy newcomers to milk market but it has been more than thousand year past. It has recently gain popularity in some parts of Europe due to its nutritional and health benefits. Donkeys belong to the family Equidae, which also includes horses and zebras. Various breeds of donkey have been domesticated around the world. The female donkey known as Jennies has been known for thousands of years for their milk [1]. The donkey milk compared with other dairy animals like goat, buffalo, sheep, cow and camel is most likely to resemble with human breast milk. Although, it was used to feed orphaned infant in the $19^{\text {th }}$ century [2]. The donkey farming becomes popular in the European countries due to their nutritional and health benefits. The female donkey produces very less quantity of milk as compared to other farming animals. One Jennies only produce about 4 cups (1 liter) of milk per day. Thus the milk is very difficult to find and considered a rare item $[1,3,4]$. It is widely available as freeze dried powdered form and an ingredient in some European-imported chocolate bars. In Italy donkey milk is key component in some infant and medical nutrceuticals [5]. On the other hand there is not any real disadvantage of this incredible gift of nature. Health experts or dieticians always suggested it should be used regularly.
But there is one disadvantage of this milk is less production due to small size of donkey udder that makes it slightly more expensive than cow milk. One liter of this nector is cost around $\$ 50$. In view of the fact the donkey milk is healthy as well as tasty truly be a perfect combination for more pleasant and responsible way of living [6] Figure 1.

\section{Nutritional characteristics of donkey milk}

The jenny milk exceptionally having high nutritional benefits amongst other farming animals milk. Production of

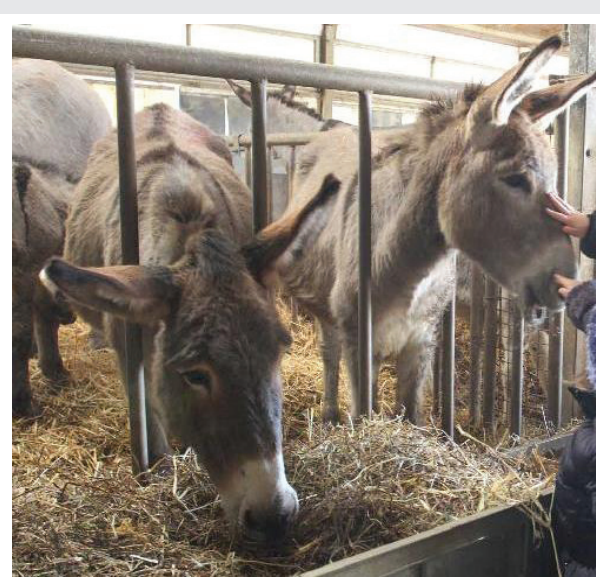

Figure 1: Donkey farming in European countries. 
jenny milk may be an interesting, profitable and alternate activity for farmers. Considering its unique nutritional category, donkey milk may be widely employed to fulfill the nutritional requirement of newborn, heart and cholesteromic patient [7]. The increasing health problem including cow milk allergy, heart disease and hypercholesteromic and other health problem, the acquisition of jenny milk will be important in clinical and nutritional aspects. Few researchers have been reported that the human breast milk and donkey milk are very much similar in nutritional value. It is the source of various vitamins and minerals along with essential proteins. It is also less in fat content and thus lowers calories and has mire vitamin $\mathrm{D}$ than other milk $[8,9]$. The nutritional information for $100 \mathrm{ml}$ of donkey milk, vitamin $-\mathrm{D}$-fortified cow milk and human breast milk depicted in Table 1 .

The donkey milk is contain very heterogeneous group of molecule including casein, whey proteins, milk fat globule proteins, enzyme and other miscellaneous minor proteins [11]. The molecules present in donkey milk shows close proximity with human milk. The protein composition of donkey milk is considerably different from cow milk. The total protein content is lower (1.5-1.8 g/100g) than cow milk and relatively similar to that of human and mare milk. Due to low protein content it put fewer loads on renal system [12]. Donkey milk contain high amount of lactose content (5.8-7.4\%) which is higher than cow milk and much similar to human milk. The high content is responsible for the good palatability of milk and facilitates the intestinal absorption of calcium that is essential for infant's bone mineralization [13]. The donkey milk mainly has three proteins viz. $\alpha$-lactalbumin, $\beta$-lactoglobulin and lysozyme. Recently, some study suggested that $\alpha$-lactalbumin has antiviral, antitumor and antistress properties. One of the main protein allergens in children is $\beta$-lactoglobulin that is the major whey protein in cow milk and absent in human milk. The content of $\beta$ - lactoglobulin in donkey milk is approximately $40 \%$ of the whey proteins which is lower than that in cow milk [14]. The donkey milk contain two forms of caseins namely, $\alpha \mathrm{S}-1$ and $\beta$-caseins that are present in different phosphorylated and glycosylated forms. These casein are present in very less amount then cow milk $[15,16]$. Some investigators suggested that the donkey milk contain lower percentage of allergen such $\beta$-lactoglobulin and $\alpha \mathrm{S}-1$ than cow milk. Due to the lower percentage of potent allergen in the donkey milk is considered hypoallergenic and suitable for the consumption for both infants and elderly people $[17,18]$.

\section{Donkey milk: Substitute of human breast milk}

In the world every animal produce a kind of breast secretion called milk to nourish their young one ensuring their growth and development. This is equally true for humans. The best milk for an infant is breast milk which is responsible for healthy and harmonious development. However, some time when it is not possible a safe and valid choice is necessary to find milk that meets the needs of the infant. While choosing the alternative milk the safety, allergic, availability, taste, nutritional component and cost given priority. Donkey milk is considered milk similar to human milk, especially regarding its nutritional component, protein composition and hypoallerginicity. Donkey milk is also an important food in the geriatric field and in cases of calcium deficiency [19]. Some investigators have shown that donkey milk has similar organoleptic characteristic to human breast milk also less allergic [20]. Due to the similarities between donkey milk and human breast milk it is not considered only food but as a nutracetical. Due to its health benefits it is not only used in early childhood nutrition, but also as a supplement in the diet of elderly people. The active ingredient similarities of $\mathrm{g} / 100 \mathrm{~g}$ of donkey milk and human breast milk shown in Table 2.

The absorption and metabolism of donkey milk is similar due to similarities in bioactive ingredients. The metabolism and function of donkey milk in human body is depicted in Figure 2.

Table1: Nutritional information of donkey milk, vitamin -D-fortified and human breast milk.

\begin{tabular}{|c|c|c|c|c|c|}
\hline \multicolumn{5}{|c|}{ Composition of Donkey's, Mare's, Human Breast and Cow's milk (g/100 g) [10]. } \\
\hline Composition & Donkey & Mare & Human Breast & Cow \\
\hline pH & $7.0-7.2$ & 7.18 & $7.0-7.5$ & $6.6-6.8$ \\
\hline Protein g/100g & $1.5-1.8$ & $1.5-2.8$ & $0.9-1.7$ & $3.1-3.8$ \\
\hline Fat g/100g & $0.3-1.8$ & $0.5-2.0$ & $3.5-4.0$ & $3.5-3.9$ \\
\hline Calories g/100g & 49 & 51 & 70 & 61 \\
\hline Carbs g/100g & 6 & 6 & 7 & 5 \\
\hline Lactose g/100g & $5.8-7.4$ & $5.8-7.0$ & $6.3-7.0$ & $4.4-4.9$ \\
\hline Total Solids (TS) g/100 g & $8.8-11.7$ & $9.3-11.6$ & $11.7-12.9$ & $12.5-13.0$ \\
\hline Casein Nitrogen (CN) g/100 g & $0.64-1.03$ & $0.94-1.2$ & $0.32-0.42$ & $2.46-2.80$ \\
\hline Whey protein g/100 g & $0.49-0.80$ & $0.74-0.91$ & $0.68-0.83$ & $0.55-0.70$ \\
\hline NPN g/100 g & $0.18-0.41$ & $0.17-0.35$ & $0.26-0.32$ & $0.1-0.19$ \\
\hline Casein Nitrogen (CN) \% & 47.28 & 50 & 26.06 & 77.23 \\
\hline Whey protein \% & 36.96 & 38.79 & 53.52 & 17.54 \\
\hline NPN \% & 15.76 & 11.21 & 20.42 & 5.23 \\
\hline Vitamin D\% & 23 & 21 & 9 & 1 \\
\hline Calcium \% & 2 & 2 & 2 & 13 \\
\hline Cholesterol \% & 3 & 3 & 5 & 3 \\
\hline Riboflavin \% & 2 & 25 & 2 & 13 \\
\hline
\end{tabular}

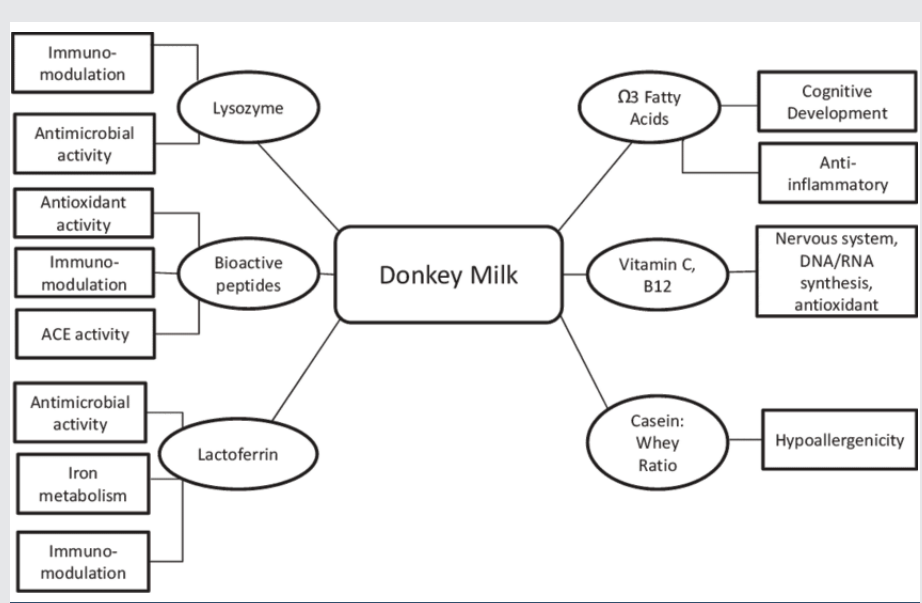

Figure 2: Metabolism and main function of donkey milk [2] 
Table 2: Percentage composition ( $\mathrm{g} / 100 \mathrm{~g}$ ) of donkey milk (evidenced in bold) and comparison with human milk [21].

\begin{tabular}{l|l|l|l|l|l|l|l} 
Milk & Water & Dry Matter & Fat & Proteins & Lactose & Ashes & Energy Value (kJ/kg)
\end{tabular}

\begin{tabular}{|l|l|l|l|l|l|l|l|}
\hline Human & 87.57 & 12.43 & 3.38 & 1.64 & 6.69 & 0.22 & 2855.6 \\
\hline
\end{tabular}

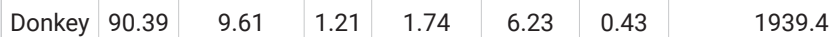

\section{Health benefits of donkey milk}

Donkey milk is most often taken due to its exceptionally high nutritional content and health benefit. Recently it has gained a lot of attention as an allergen friendly and immune boosting properties. Compared with the protein in cow's milk, which has about five times more casein than whey, the protein in donkey milk has roughly equal parts casein and whey [23]. Given its significantly lower casein content, many people with a cow's milk protein allergy can tolerate donkey milk, as they find that donkey milk does not cause an allergic response [23]. In an Italian in 81 children who has allergy to cow milk, swapping to donkey milk found that all were able to digest it without any allergic or negative interaction with regular height and weight gain [24]. Another important component of donkey milk is lactose. It helps body to absorb calcium, which is important for strong bones $[23,25]$. The other component present in donkey milk mainly vitamin D may support healthier immune system and lower cardiovascular disorders. A lab study had shown that donkey milk able to induced cytokines production, the protein that stimulate to boost immunity. In the same study it was found that donkey milk also signals cells to produce nitric oxide, a compound that dilate blood vessel thus improve blood flow and reduce blood pressure [26].

\section{Role of donkey milk in nutrition}

Natural hypoallergenic milk for infants: Cow milk protein allergy (CMPA) is a common food allergy among children age below 3 years. On the other hand the donkey milk is used as natural hypoallergenic milk without any adverse effect among the users [27]. Several studies shown that the donkey milk is less allergic than cow milk. In the late $20^{\text {th }}$ century it was used to feed orphaned infants and sick children in the European countries due to its excellent bioactive molecules. Donkey milk is very much resemblance with the human breast milk for its lactose, protein and minerals. The donkey milk having the immune active compound such as lysozyme and lactoferrin probably boosting the immune system of the infants. Donkey milk supplemented with vegetable oil $(4 \mathrm{ml} / 100 \mathrm{ml})$ mimic breast milk $[28,29]$.

\section{Fermented donkey milk}

Equid i.e. donkey and mare milk widely used as a suitable medium for probiotic beverage production by using lactobacillus bacteria. Koumiss fermented equid milk used in central Asia from ancient time [30]. Koumiss is the national drink, of Mongolia. The mongolian have a saying that 'kumys cures 40 diseases [31].

\section{Cosmetics with donkey milk}

In modern times the cosmetic industry mainly focused on the products made with natural ingredients. The milk origin is natural and it is a key ingredients widely used in the cosmetic industry. Various scientific studies have proven that the cosmetic products containing donkey milk showed exceptional high benefits for the skin [32]. The donkey milk is enrich in protein, minerals, essential fats, bioactive enzymes and various growth factors like riboflavin, vitamin D etc. provide natural nourishment to skin and toned it. The donkey milk naturally contain antibacterial compound such as lysozyme and lactoferrin inhibit the growth of pathogenic bacteria on skin and reduce the rate of skin infection $[33,34]$. Due to these properties the donkey milk formulated with some chemical may used to treat acne, psoriasis, eczema and other related skin infection. Nowadays, donkey milk is also used in the manufacturing of soap and face cream [35].

\section{Conclusion}

Donkey has accompanied our lives since ancient times. The mules are used for agricultural activities. But on the other hand female donkeys are of great interest due to their milk. The donkey milk reported that this is very much closest to human breast milk with great health benefit. In the late $20^{\text {th }}$ century the donkey milk used to feed the orphaned and sick children in the European countries. The donkey milk is also less allergic than cow milk so it can help in replacing cow milk protein allergy (CMPA). Due to its pleasant and sweet taste this could be easily included in children's menu. The donkey milk also enrich with vitamin $\mathrm{C}$ (60 times more than cow's milk) , A , D, E, omega -3 and -6 fatty acids, minerals such as calcium, zinc and magnesium suitable for the growth and development of children. Apart from this the donkey milk also strengthens immunity and other respiratory tract infection such as tuberculosis, bronchitis, pneumonia, cough and asthma. It is also more than beneficial for those suffering from osteoporosis and other bone illnesses due to high percentage of vitamin $\mathrm{D}$ and calcium. It is also used in cosmetic industry for the formulation of different soap and cream. Still there is vast gap and research and development is required in this field to explore the more health and nutritional benefits of donkey milk.

\section{References}

1. Elisabetta S, Francesco F (2012) Equid milk for human consumption. Int Dairy Journal 24: 130-142. Link: https://bit.ly/2HFshLJ

2. Aspri, Maria, Economou, Nicole, Papademas, Photis (2017) Donkey milk: An overview on functionality, technology, and future prospects. Food reviews international 33: 316-333. Link: https://bit.ly/30t8zJE

3. Aganga AA, Lesto M, Aganga AO (2000) Feeding donkeys. Livest Res Rural Dev 12: 1-5.

4. Beghelli D, Roscini A, Valiani A, Vincenzetti S, Cavallucci C, et al. (2009) Somatic and differential cell count during a lactation period ass milk. Int Dairy J 19: 691-693. Link: https://bit.ly/3I5R1ex

5. Cosentino C, Freschi P, Paolino R, Valentini V(2013) Market sustainability analysis of jenney milk cosmetics. Emir J Food Agric 25: 635-640. Link: https://bit.ly/34IFvoA

6. Aspri M, Economou N, Papademas P (2017) "Donkey milk: An overview on functionality, technology, and future prospects," Food Reviews International 33: 316-333. Link: https://bit.ly/34kYekj 
7. Swar OM (2011) Donkey milk-based formula: A substitute for patients with cow's milk protein allergy. Sudan J Paediatr 11: 21-24. Link: https://bit.ly/3l6EveV

8. Martini M, Altomonte I, Licitra R, Salari F (2018) Nutritional and Nutraceutical Quality of Donkey Milk. Journal of equine veterinary science 65: 33-37. Link: https://bit.ly/3cRFTPO

9. Miraglia N, Salimei E, Fantuz F (2020) Equine Milk Production and Valorization of Marginal Areas-A Review. Animals (Basel) 27: 393-400. Link: https://bit.ly/3jniqYR

10. Doreau M, Martin-Rosset W (2011) Animals that produce dairy foods horse. In Encyclopaedia of dairy sciences (2nd ed.), Fuquay JW, Fox PF \& McSweeney PLH, eds., San Diego, CA, USA: Academic Press.1: 358-364. Link: https://bit.ly/3ndE8km

11. Huang F, Kim JS (2012) IgE-mediated cow's milk allergy in chil- dren. Pediatric Allergy and Immunology 12: 630-640.

12. Malacarne M, Martuzzi F, Summer A, Mariani P (2002) Protein and fat composition of mares milk: some nutritional remarks with reference to human and cows' milk. International Dairy Journal 12: 869-877. Link: https://bit.ly/2HSVW4t

13. Chiofalo B, Dugo P, Bonaccorsi IL, Mondello L (2011) Comparison of major lipid components in human and donkey milk: new perspectives for a hypoallergenic diet in humans. Journal of Immunopharmacology Immunotoxicology 1: 1-13. Link: https://bit.ly/2ShQYjp

14. Miranda G, Mahe MF, Leroux C, Martin P (2004) Proteomic tools to characterizethe protein fractions of equidae milk. Proteomics 4: 2496-2509. Link: https://bit.ly/33iGpD8

15. Bertino E, Gastaldi D, Monti G, Baro C, Fortunato D, et al. (2010) Detailed proteomic analysis on donkey milk insight into its hypoallergenicity. Front Biosci 2: 526-536. Link: https://bit.ly/36oapPN

16. Creamer LK (2002) Milk proteins/casein nomenclature, structure and association properties. In: H. Roginski, J.W. Fuquay, P.F. Fox (Eds.) Enciclopedia of Dairy Science, London, UK: Academic Press, Elsevier Science 1895-1902.

17. Carroccio A, Cavataio F, Montalto G, D'Amico D, Alabrese L, et al. (2000) Intolerance to hydrolysed cow's milk proteins in infants: clinical characteristics and dietary treatment. Journal of Clinical and Expermental Allergy 30: 1597 1603. Link: https://bit.ly/3jnhdAN

18. Businco L, Giampietro PG, Lucenti P, Lucaroni F, Pini C, et al. (2000) Allergenicity of mare's milk in children with cow's milk allergy. Journal of Allergy and Clinical Immunology 105: 1031-1034. Link: https://bit.ly/2HQJNNh

19. Malissiova E, Arsenos G, Papademas P, Fletouris D, Manouras A, et al. (2016) Assessment of donkey milk chemical, microbiological and sensory attributes in greece and cyprus. International Journal of Dairy Technology 69: 1-8. Link: https://bit.ly/36D0syn

20. Mao X, Gu J, Sun Y, Xu S, Zhang X, et al. (2009) Anti-proliferative and antitumour effect of active components in donkey milk on $A 549$ human lung cancer cells. International Dairy Journal 19: 703-708. Link: https://bit.ly/3I0Wi72
21. Mariani PL (2008) Donkey milk nutraceutical characteristics: a biochemica evaluation of nutritious and clinical properties. Unpublished Doctorate Thesis, University of Camerino. Italy. Link: https://bit.ly/34gCbet

22. Monti G, Bertino M, Muratore, MC, Coscia A, Cresi F, et al. (2007) Efficacy of donkey's milk in treating highly problematic cow's milk allergic children: an in vivo and in vitro study. Pediatr Allergy Immunol 18: 258-264. Link: https://bit.ly/3nc2tY4

23. Brumini D, Criscione A, Bordonaro S, Vegarud G, Elisabeth M, et al. (2016) Whey proteins and their antimicrobial properties in donkey milk: a brief review. Dairy science \& technology 4: 11-14. Link: https://bit.ly/36ol4sl

24. Sicherer SH (2011) Epidemiology of food allergy. J Allergy Clin Immunol 127 594-602. Link: https://bit.ly/36pq4ON

25. Jirillo F, Jirillo E, Magrone T (2010) Donkey's and goat's milk consumption and benefits to human health with special reference to the inflammatory status. Curr Pharm Des 16: 859-863. Link: https://bit.ly/30otgXq

26. Yvon S, Olier M, Leveque M, Jard G, Tormo H, et al. (2018) Donkey milk consumption exerts anti-inflammatory properties by normalizing antimicrobia peptides levels in Paneth's cells in a model of ileitis in mice. Eur J Nutr 57: 155 166. Link: https://bit.ly/34IC9IL

27. Fiocchi A, Brozek J, Schünemann H, Bahna L, von Berg A, et al. (2010) World Allergy Organization (WAO) Diagnosis and Rationale for Action against Cow's Milk Allergy (DRACMA) Guidelines. World Allergy Organ J 3: 157-161. Link: https://bit.ly/2GIC6hz

28. Guo HY, Pang K, Zhang XY, Zhao L, Chen SW, et al. (2007) Composition Physiochemical Properties, Nitrogen Fraction Distribution, and Amino Acid Profile of Donkey Milk. Journal of Dairy Science 90: 1635-1643. Link: https://bit.ly/34hedzN

29. Tidona F, Sekse C, Criscione A, Jacobsen M, Bordonaro S, et al. (2011) Antimicrobial effect of donkeys' milk digested in vitro with human gastrointestinal enzymes. International Dairy Journal 21: 158-165. Link: https://bit.ly/2Gtq5GN

30. Salimei E, Fantuz F (2012) “Equid milk for human consumption”. International Dairy Journal 24: 130-142. Link: https://bit.ly/3cPpxa2

31. Uniacke-Lowe T (2011) Koumiss. In J. W. Fuquay, P. F. Fox, \& P. L. H. McSweeney (Eds.) (2nd ed.). Encyclopedia of dairy sciences, 2: 512-e517.

32. Cosentino C, Freschi P, Valentini R, Paolino P (2013) "Market sustainability analysis of jenny milk cosmetics". Emirates Journal of Food and Agriculture 25: 635-640. Link: https://bit.ly/33ml5fV

33. Vincenzetti S, Savini M, Cecchini C, Micozzi D, et al. (2011) Effects of Lyophilization and Use of Probiotics on Donkey's Milk Nutritional Characteristics. Int J Food Eng 7: 30-32. Link: https://bit.ly/3ioktus

34. Alessandri C, Mari A (2007) Efficacy of donkey's milk in treating cow's milk allergic children: major concerns. Pediatr Allergy Immunol 18: 625-626. Link: https://bit.ly/3I6Bifn

35. Conte F, Passantino A (2008) Isolation of Enterobacter sakazakii from ass milk in Sicily: case report, safety and legal issues. Travel Med Infect Dis 6: 250-252. Link: https://bit.ly/36pBnGT

Copyright: (c) 2020 Prasad B. This is an open-access article distributed under the terms of the Creative Commons Attribution License, which permits unrestricted use distribution, and reproduction in any medium, provided the original author and source are credited. 